\title{
A new species of Parastrigea (Digenea, Strigeidae) endoparasite of Buteogallus urubitinga (Aves, Accipitridae) from Argentina
}

\author{
F. B. DRAGO, L. I. LUNASCHI \\ Laboratorio de Helmintología, División Zoología Invertebrados. Museo de La Plata, Facultad de Ciencias \\ Naturales y Museo, UNLP, Paseo del Bosque S/Nº 1900 La Plata, Buenos Aires, Argentina, \\ E-mail:fdrago@fcnym.unlp.edu.ar
}

\begin{abstract}
Summary
A new strigeid digenean, Parastrigea macrobursa n. sp., is described from specimens recovered from the small intestine of the great black-hawk, Buteogallus urubitinga (Aves: Accipitridae), from Formosa Province, Argentina. The new species is characterized by having a tulip-shaped forebody, a hindbody without neck region, a large, well delimited copulatory bursa, and a very deep genital atrium. Three species of Parastrigea share the shape of the copulatory bursa namely $P$. faini, $P$. astridae and $P$. tulipoides. Parastrigea faini and $P$. astridae differ mainly from the new species by having the forebody strongly divided in two regions and very developed lateral expansions, and Parastrigea tulipoides by having a long neck region and a longer body size. This new species represents the first record of a member of the genus Parastrigea Szidat, 1928 parasitizing birds from Argentina. A key is presented for the species currently recognized as valid in the genus.
\end{abstract}

Keywords: Strigeidae; Parastrigea macrobursa n. sp.; Buteogallus urubitinga; Accipitridae; Argentina

\section{Introduction}

The great black-hawk, Buteogallus urubitinga (Gmelin) (Accipitridae), is a diurnal bird of prey found in the open savanna and swamp edges of the Neotropical Region, from Mexico through Central América to Bolivia, Uruguay and central Argentina (Thiollay, 1994). The helminth fauna of the great black-hawk is scarcely known, to date it was reported as host of four species of parasites in Brazil, Thelazia (Thelaziella) aquilina Baylis, 1934 (NematodaThelaziidae), Contracaecum caballeroi Bravo-Hollis, 1939 (Nematoda- Anisakidae), Neodiplostomum microcotyle Dubois, 1937 (Digenea-Diplostomidae), and Oligacanthorhynchus iheringi Travassos, 1916 (Acanthocephala-Oligacanthorhynchidae) (Travassos, 1917; Dubois, 1937; Pinto et al., 1994).
Helminths collected recently from the intestine of the great black-hawk in Argentina included an undescribed species of Parastrigea Szidat 1928 (Strigeidae), which is described and illustrated in the present paper.

\section{Materials and methods}

Four specimens of Buteogallus urubitinga were collected between October 2004 and September 2009 from La Marcela farm (26 $17^{\prime} 35^{\prime}$ 'S, 5906'67’W), Pirané, Formosa Province, Argentina. The birds were captured with a shotgun and dissected in the field, the viscera preserved in $10 \%$ formalin and transported to the laboratory for examination. The digeneans found were stored in $70 \%$ ethanol, stained with a 1:6 dilution in $96 \%$ ethanol of hydrochloric carmine, dehydrated and mounted in Canada balsam between cover glasses in order to facilitate handling and observation. Transversal serial sections $(5 \mu \mathrm{m}$ thick) of forebody were stained with haematoxylin-eosin and mounted in Canada balsam. The drawings were made with the aid of a drawing tube. Measurements are given in micrometres $(\mu \mathrm{m})$ unless otherwise stated, as the range followed by the mean in parentheses. Type and voucher specimens of parasites and hosts were deposited in the Helminthological and Ornithological Collections of the Museo de La Plata (MLP), La Plata, Argentina, respectively.

\section{Results and discussion}

Parastrigea macrobursa n. sp. (Fig.1)

Description (based on 11 specimens): Body distinctly bipartite, $1.189-2.117 \mathrm{~mm}(1.764 \mathrm{~mm})$ in total length. Forebody tulip-shaped, with large opening and lateral expansions poorly developed; $435-783 \times 348-638$ (568 $\mathrm{x}$ 455). Tegument smooth. Hindbody plump, without neck 

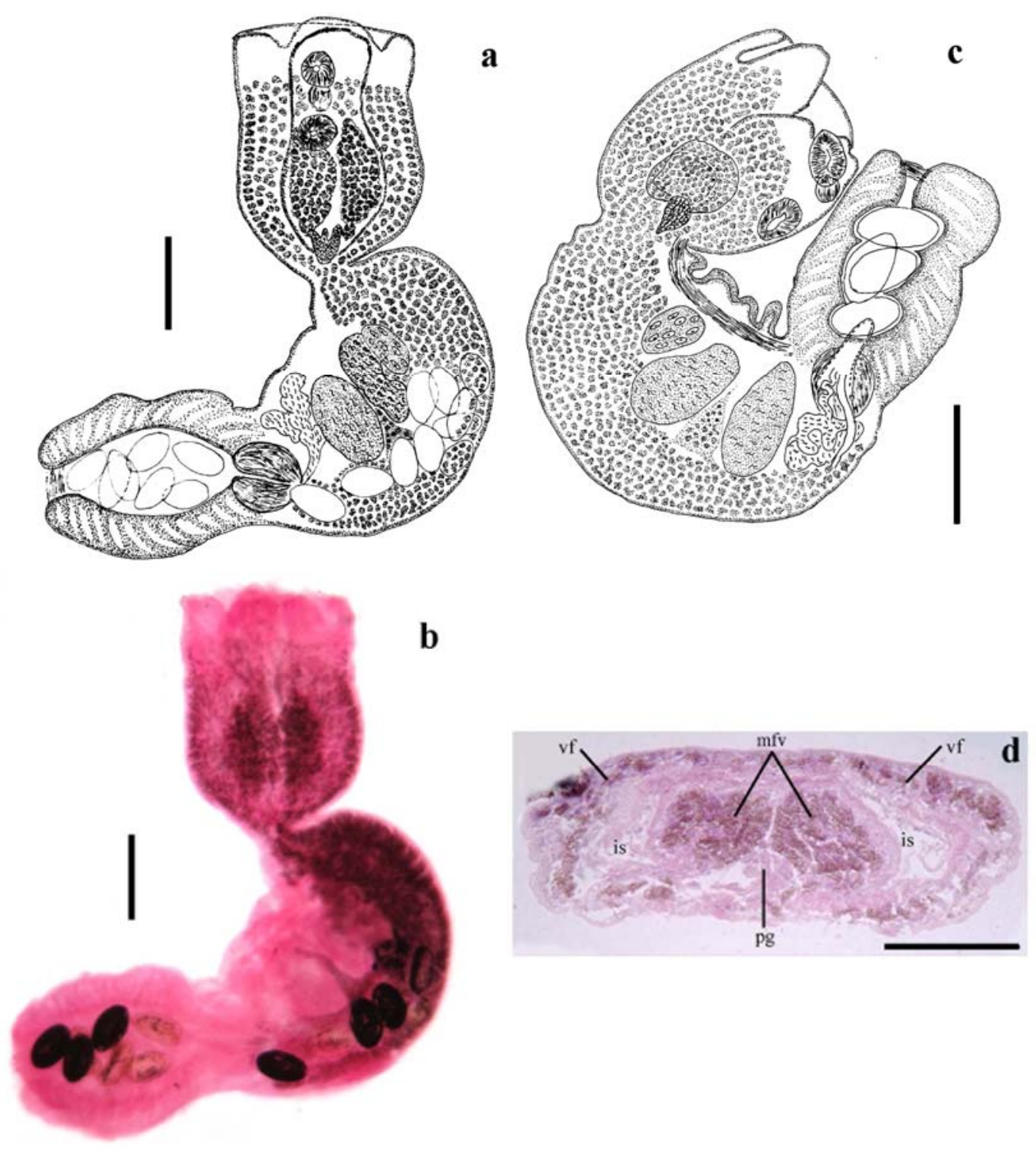

Fig. 1. Parastrigea macrobursa n. sp.

region, 2 - 3 times longer than forebody; $754-1451$ x 391 - 658 (1196 x 539). Ratio of body length to forebody length $1: 2.7-4.1(1: 3.1)$. Ratio hindbody length to forebody length $1: 1.7-3.1(1: 2.1)$. Oral sucker subterminal, well developed, $76-87$ × $64-99$ (82 x 77). Ventral sucker spherical to oval, $82-107$ x $60-150$ (93 x 106) wide. Distance between suckers 26 - 97 (56). Suckerwidth ratio $1: 0.9-1.8$ ( $1: 1.4)$. Holdfast organ lobes reaching anterior end. Proteolytic gland at base of forebody $64-83$ x $60-76$ (71 x 69). Prepharynx absent; pharynx $44-60 \times 39-60$ (54 × 52); oesophagus not seen; intestinal caeca narrow, reaching copulatory bursa. Testes in tandem, large, oval or cuneiform, anterior testis $97-155 \mathrm{x}$ 188 - 262 (124 x 213); posterior testis $102-213$ x $193-$ 304 (157 x 248). Seminal vesicle long, folded on itself, behind posterior testis. Ovary oval, pre-testicular or slightly overlapping anterior testis, at 133 - 299 (212) from intersegmental constriction $(13-27 \%$ of hindbody length), 69 - 131 x 109 - 190 (87 x 138). Laurer's canal short, opening dorsally between ovary and anterior testis. Mehlis' gland in intertesticular region. Vitelline follicles similar in size in both body segments; in forebody, extending from oral sucker in the dorsal wall of body, and from ventral sucker in the ventral wall; in the dorsal lip of holdfast organ forming two symmetrical masses situated between ventral sucker and intersegmental constriction; in hindbody strongly concentrated in preovarian region, extending ventrally to posterior testis or seminal vesicle. Uterus containing 3 - 45 (19) large eggs; 92 - 143 x 57 77 (117 x 69). Ratio of body length to egg length $1: 10-$ 20 (1 : 15). Copulatory bursa large, delimited by pronounced constriction, occupying 30\%-45\% (40\%) of hindbody length; 290 - 648 x 280 - 532 (489 x 396). Muscular ring (Ringnapf) absent. Genital cone well delimited from body parenchyma, 117 - 179 x $107-176(151$ x 134); ejaculatory duct and uterus join at base of genital 
Table 1. Records of the Neotropical species of Parastrigea, indicating their hosts and geographical distributions

\begin{tabular}{|c|c|c|c|}
\hline Species & Host & Locality & References \\
\hline \multirow[t]{9}{*}{ P. brasiliana } & Cochlearius cochearius (L.) & Brazil & Dubois (1968) \\
\hline & Nyctanassa violacea (L.), Butorides striatus (L.) & Brazil & Arruda et al.(2001)* \\
\hline & \multirow[t]{2}{*}{ Ardea alba egretta Gmelin } & Venezuela & Gomes \& Oliveira Rodrigues (1981) \\
\hline & & Brazil & Noronha et al. (2009) \\
\hline & Ardea alba $\mathrm{L}$. & USA & Gibson et al. (2005)* \\
\hline & Ardea herodias & USA & Gibson et al. (2005) \\
\hline & Egretta thula (Molina) & Brazil & Gibson et al. (2005) \\
\hline & Falconidae & Brazil & Noronha et al. (2009) \\
\hline & Tigrisoma lineatum (Boddaert) & Brazil & Noronha et al. (2009) \\
\hline P. caballeroi & Jabiru mycteria (Lichtenstein), Mycteria americana $\mathrm{L}$. & Venezuela & Gomes \& Oliveira Rodrigues (1981) \\
\hline \multirow[t]{5}{*}{ P. cincta } & Phimosus infuscatus berlepschi Hellmayr & Colombia & Uribe-Piedrahita $(1948)^{* *}$; Dubois (1968) \\
\hline & Ardea sp. & Brazil & Dubois (1968) \\
\hline & Falco sparverius sparverius L., Ajaia ajaja (L.) & Cuba & Dubois \& Macko (1972) \\
\hline & Micrastur gilvicollis (Vieillot) & Brazil & Dubois (1970) \\
\hline & J. mycteria & Venezuela & Lamothe-Argumedo et al. (1997) \\
\hline \multirow[t]{5}{*}{ P. mexicana } & \multirow[t]{3}{*}{ Recurvirostra americana Gmelin } & Mexico & Coil (1957) \\
\hline & & USA, Canada & Gibson et al. (2005) \\
\hline & & Cuba & Gibson et al. (2005) \\
\hline & \multirow[t]{2}{*}{ Himantopus mexicanus (Müller) } & USA & Dubois \& Macko (1972) \\
\hline & & USA & Hinojos \& Canaris (1988) \\
\hline \multirow[t]{3}{*}{ P. diovadena } & \multirow[t]{2}{*}{ Eudocimus albus (L.) } & Cuba & Dubois \& Macko (1972) \\
\hline & & USA & Bush \& Forrester (1976) \\
\hline & Eudocimus ruber (L.) & Colombia & Dubois (1978) \\
\hline
\end{tabular}

*Cited as Apharyngostrigea brasiliana (Szidat, 1928) Szidat, 1929

**Cited as Strigeidae

cone forming hermaphroditic duct. Genital atrium very deep; genital pore terminal. Excretory vesicle not observed. Excretory pore dorso-subterminal at level of copulatory bursa.

Type host: Buteogallus urubitinga (Gmelin) (Falconiformes, Accipitridae).

Type locality: La Marcela farm (26 17'35'S; 5906’67’W), Pirané, Formosa Province, Argentina.

Date of collection: October 2004, September 2009.

Site of infection: small intestine.

Type material: Holotype MLP 6272; paratypes MLP 6273, 6274 (8 specimens).

Voucher specimens: MLP 6275 in cross-sections, MLP 6276 (2 specimens)

Prevalence: 3 of 4 (75\%).

Mean intensity: $7.3(3-13)$.

Etymology: The specific name refers to the large size of the copulatory bursa.

Remarks: Parastrigea is a genus that includes species characterized by having the forebody with two lateral and symmetrical expansions originated by the concentration of vitelline follicles in the dorsal lip of the holdfast organ. The main morphologic characteristics used to distinguish among its species are the shape of forebody, lateral expansions and testes, the presence or absence of neck region in hindbody and the conformation and size of the copulatory bursa, genital cone and genital atrium (Dubois, 1968). At present, this genus contains 17 species, 5 of them described in the Neotropical Region as parasites of ciconiiform, falconiform and charadriiform birds: P. brasiliana (Szidat, 1928) Dubois, 1964, P. caballeroi Dubois, 1952, P. cincta (Brandes, 1888) Szidat, 1928, P. diovadena Dubois et Macko, 1972, and P. mexicana Coil, 1957 (Table 1). Moreover, a sixth species, $P$. robusta Szidat, 1928, was listed in Brazil parasitizing Jacana spinosa jacana (L.) by Noronha et al., (2009), although Dubois (1970) considered questionable this report for South America, given the poor condition of the specimens. In Argentina, P. brasiliana was listed parasitizing ardeid birds (Lunaschi et al., 2007), however, these specimens were transferred to Apharyngostrigea ardearum (Lutz, 1928) Dubois, 1968 (Drago \& Lunaschi, 2011).

According to descriptions given by Dubois (1968), $P$. macrobursa $\mathrm{n}$. sp. differs from other Neotropical species of the genus by a combination of characters, and principally by having a large well delimited copulatory bursa, with a well delimited genital cone from body parenchyma and a very deep genital atrium. $P$. brasiliana can be easily distinguished from the new species by having the forebody divided in a campaniform anterior region that includes both suckers, and a pyriform posterior region with lateral pronounced expansions. In addition, this species differs by possessing a long neck region in hindbody ( $1 / 3$ of body length) occupied entirely by vitelline follicles, testes 


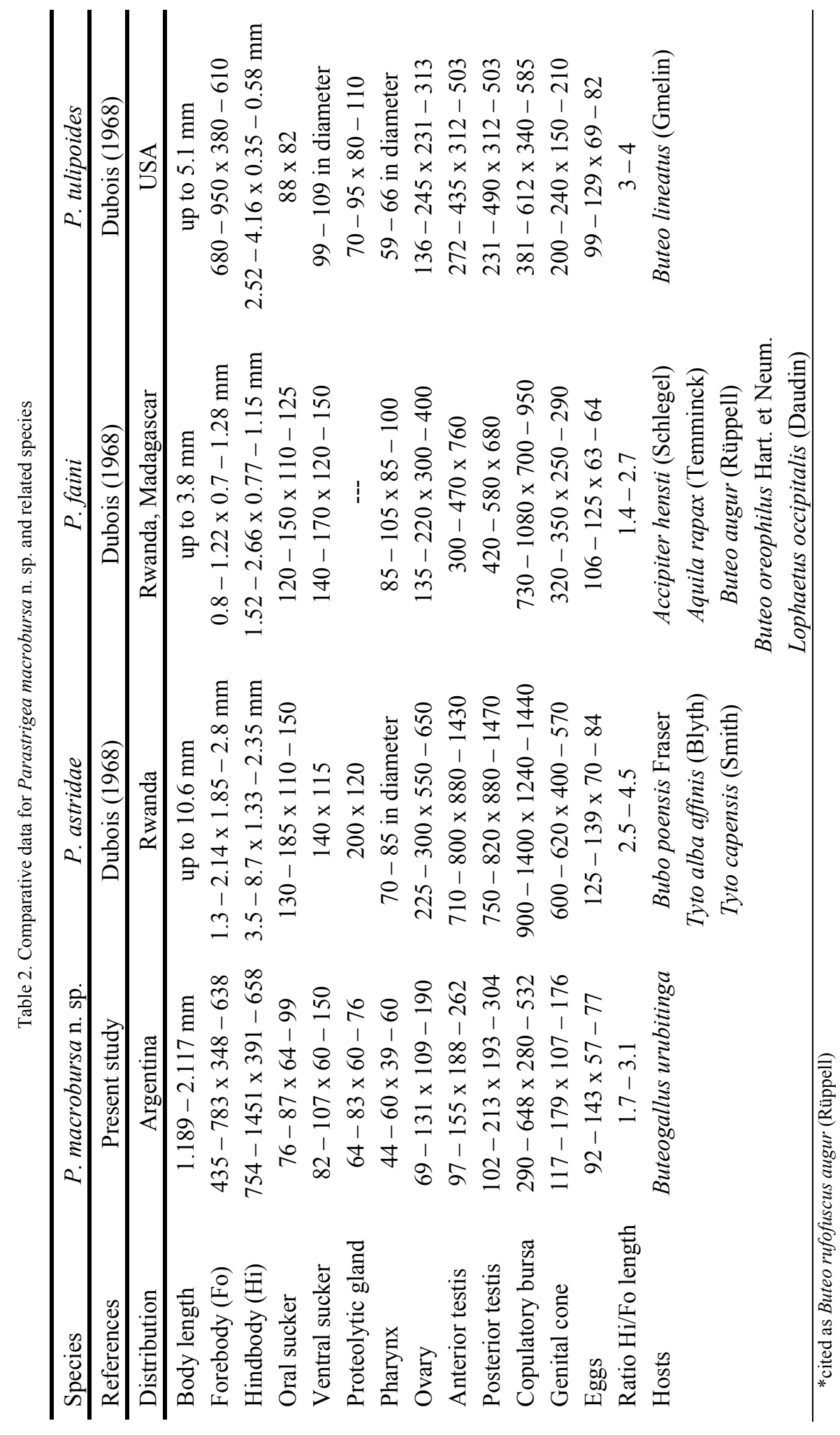


Key to the species of Parastrigea

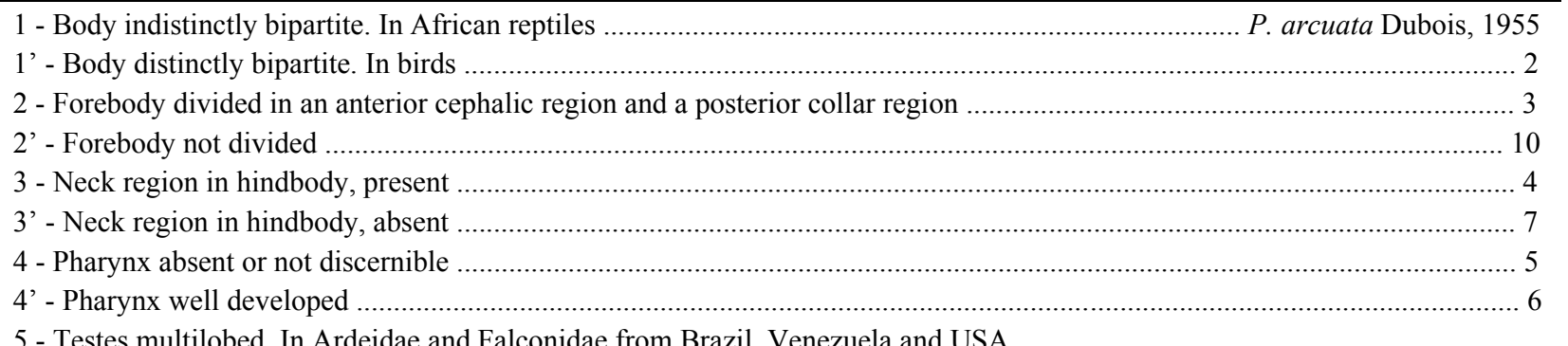

5 - Testes multilobed. In Ardeidae and Falconidae from Brazil, Venezuela and USA

P. brasiliana (Szidat, 1928) Dubois, 1964

5' - Testes bilobed. In Accipitridae and Laridae from Palearctic region

6 - Copulatory bursa with Ringnapf; genital atrium campaniform. In Accipitridae from USA

P. flexilis (Dubois, 1934) Dubois, 1955

P. campanula Dubois et Rausch, 1950

6' - Copulatory bursa without Ringnapf; genital atrium not campaniform. In Ciconiidae from Rwanda and India

7 - Copulatory bursa with Ringnapf; genital atrium shallow

P. thienponti Dubois et Fain, 1956

7' - Copulatory bursa without Ringnapf; genital atrium very deep ............................................................................... 9

8 - Genital cone small. In Ardeidae, Ciconiidae, Threskiornithidae, Falconidae and Recurvirostridae from the Neotropical region P. cincta (Brandes, 1888) Szidat, 1928

8' - Genital cone enormeous. In Accipitridae from Alaska. ........................................ P. ogchnocephala Dubois et Rausch, 1950

9 - Hindbody $<3 \mathrm{~mm}$; ratio hindbody/forebody length $1.4-2.7$; copulatory bursa occupying $35 \%-50 \%$ of hindbody. In

Accipitridae from Rwanda and Madagascar. (in Rattus rattus L. as accidental host) ................................ P. faini Dubois, 1955

9' - Hindbody >3 mm; ratio hindbody/forebody length $2.5-4.5$; copulatory bursa occupying $25 \%-33 \%$ of hindbody. In

Tytonidae and Strigidae from Africa ............................................................................................... P. astridae Dubois, 1955

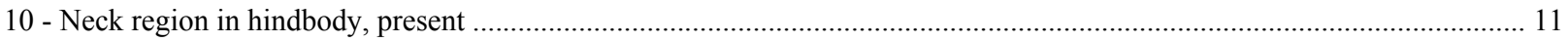

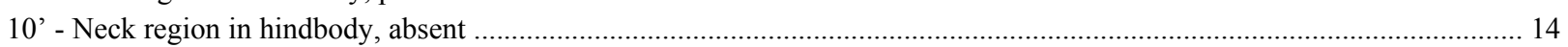

11 - Pharynx absent. In Accipitridae and Ardeidae from Australia .................................... P. repens (Chase, 1921) Dubois, 1961

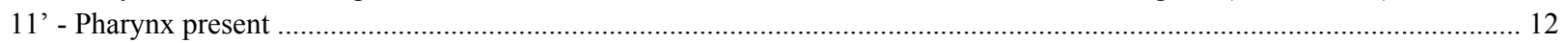

12 - Neck region occupying $50 \%$ of hindbody In Accipitridae from Philippines and Europe ........ P. intermedia Tubangui, 1932

12 ' - Neck region occupying $60-75 \%$ of hindbody .............................................................................................. 13

13 - Forebody ovoid; copulatory bursa small; testes entire. In Accipitridae from Europe

P. tenuicollis (Westrumb, 1823) Dubois, 1966

13' - Forebody tulip-shaped; copulatory bursa large, testes bilobed. In Accipitridae from USA

P. tulipoides Miller et Harkema, 1965

14 - Proteolytic gland similar in size to ovary. In Threskiornithidae from Cuba, USA and Colombia

P. diovadena Dubois et Macko, 1972

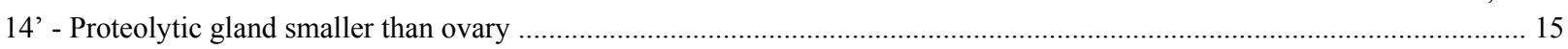

15 - Forebody with lateral expansions poorly developed. Genital atrium very deep. In Accipitridae from Argentina

P. macrobursa n. sp.

15 ' - Forebody with lateral expansions well developed. genital atrium slightly deep ........................................................ 16

16 - Body $>5$ mm; hindbody cylindrical. In Ciconiidae from Venezuela .......................................... P. caballeroi Dubois, 1952

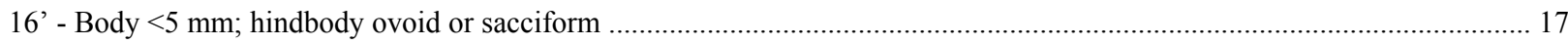

17 - Copulatory bursa with Ringnapf. In Falconidae, Podicipedidae and Anatidae from Holarctic region

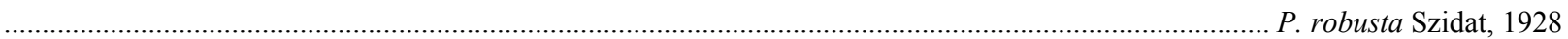

17' - Copulatory bursa without Ringnapf. In Recurvirostridae from Cuba and North America ................. P. mexicana Coil, 1957

multilobed, muscular ring "ringnpf" in the copulatory bursa, no discernible pharynx, longer specimens (body up to 7.6 $\mathrm{mm}$ vs. $1.2-2.1 \mathrm{~mm}$ ), and a greater ratio of hindbody length to forebody length $(1: 3.1-4.8$ vs. $1.7-3.1)$. Parastrigea caballeroi can be differentiated from $P$. macrobursa n. sp. by having a sacciform forebody, strongly arched dorsally with reniform lateral expansions, multilobed testes, longer specimens (body up to $6.4 \mathrm{~mm}$ ), and smaller eggs (87 -91 x $41-53$ vs. $92-143$ x $57-77$ ). Parastrigea cincta differs from the new species by having a pyriform forebody with a small opening, divided in two regions, of which the posterior region has very protuberant lateral expansions, multilobed testes, greater length of body (body up to $15 \mathrm{~mm}$ ), and smaller eggs ( $80 \times 50$ vs. $92-143 \times 57-77$ ). 
P. mexicana is similar in size to P. macrobursa n. sp. (body up to $2.3 \mathrm{~mm}$ vs. $1.2-2.1 \mathrm{~mm}$ ), but differs by the shape of forebody, which is piriform with a small opening and very developed lateral expansions, by the location of the proteolytic gland, which is situated in the middle of the holdfast organ and by having the posterior end of hindbody rounded, where the copulatory bursa is not delimited externally. Parastrigea diovadena differs mainly by having a larger bilobed proteolytic gland, a small copulatory bursa slightly delimited externally and a well developed muscular ring "ringnpf", a shallow genital atrium and strongly lobed testes. Other species of the genus, i.e. Parastrigea faini Dubois, 1955 and Parastrigea astridae Dubois, 1955 from the Ethiopian Region, and Parastrigea tulipoides Miller et Harkema, 1965 from the Nearctic Region, are similar to the new species by having a large copulatory bursa, well delimited externally, and with a very deep genital atrium, but differ in most metrical characters (Table 2). Moreover, $P$. faini can be easily distinguished from P. macrobursa n. sp. by possessing the forebody strongly divided in an anterior cephalic region, bulbiform or cylindrical, and a posterior region with very pronounced lateral expansions. Parastrigea astridae can be differentiated by having the forebody divided in two regions, a bulbiform anterior region and a posterior region strongly dilated bearing very protuberant lateral expansions and multilobed testes. Finally, P. tulipoides is similar to P. macrobursa n. sp. in the shape of forebody and copulatory bursa, but differs by having a long neck in the hindbody and bilobed testes.

Based on all these differences, a new species Parastrigea macrobursa $\mathrm{n}$. sp. is proposed.

\section{Acknowledgements}

To Luis Pagano and Ignacio Roesler for assistance in collecting the hosts. The authors, Lía Lunaschi and Fabiana Drago, are members of the Comisión de Investigaciones Científicas de la provincia de Buenos Aires (CIC) and Universidad Nacional de La Plata (UNLP), respectively. The present study was funded by CIC (Res. No ${ }^{\circ} 1150 / 09$ ) and UNLP (11/N541).

\section{References}

Arruda, V. S., Pinto, R. M., Muniz-Pereira, L. C. (2001): New host and geographical records for helminths parasites of Ardeidae (Aves, Ciconiiformes) in Brazil. Rev. Bras. Zool., 18(Supl. 1): 225 - 232. DOI: 10.1590/S010181752001000500018.

Bush, A. O., Forrester, D. J. (1976): Helminths of the white ibis in Florida. P. Helm. Soc. Wash., 43(1): $17-23$.

CoIL, W. H. (1957): Parastrigea mexicanus sp. nov., a strigeid trematode from the avocet. T. Am. Microsc. Soc., 76: $70-72$
Drago, F., LunASCHI, L. (2011): Digenean parasites of Ciconiiform birds from Argentina. Rev. Mex. Biodiv., 82: $77-83$

DuboIs, G. (1937): Sur quelques Strigéidés (Notes préliminaires). Rev. Suisse Zool., 44(25): 391 - 396

DuBoIs, G. (1968): Synopsis des Strigeidae et des Diplostomatidae (Trematoda). Mém. Soc. Neuchâtel. Sci. Nat., 10: $1-258$

DuboIS, G. (1970): Les Strigeata (Trematoda) de la collection A. Lutz. Mem. I. Oswaldo Cruz, 68(1): 169 - 196. DOI: $10.1590 / \mathrm{S} 0074-02761970000100006$.

DuBoIs, G. (1978): Notes Helminthologiques IV: Strigeidae Railliet, Diplostomidae Poirier, Proterodiplostomidae Dubois et Cyathocotylidae Poche (Trematoda). Rev. Suisse Zool., 85(3): $607-615$

Dubois, G., MAcko, J. (1972): Contribution a l'étude de Strigeata La Rue, 1926 (Trematoda: Strigeida) de Cuba. Ann. Parasit. Hum. Comp., 47(1): 51 - 75

Gibson, D. I., BrAY, R. A., HARris, E. A. (2005): HostParasite Database of the Natural History Museum, London. Retrieved August 21, 2010 from http://www.nhm. ac.uk/research-curation/research/projects/host-parasites

Gomes, D. C., De Oliveira Rodrigues, H. (1981): Trematoda. In: Hurlbert, S. H., Villalobos FigueroA, A. (Eds). Aquatic Biota of Mexico, Central America and the West Indies, California, USA, San Diego State University, pp. $116-128$

Hinojos, J. G., CANARIS, A. G. (1988): Metazoan Parasites of Himantopus mexicanus Müller (Aves) from Southwestern Texas, with a Checklist of Helminth Parasites from North America. J. Parasitol., 74(2): 326 - 331

LAmothe-Argumedo, R., García-Prieto, L., OsorioSARABIA, D., PÉrez-Ponce De León, G. (1997): Catálogo de la Colección Nacional de Helmintos. México D. F, México, UNAM-CONABIO, 211 pp.

Lunaschi, L. I., Cremonte, F., Drago, F. B. (2007): Checklist of digenean parasites of birds from Argentina. Zootaxa, 1403: 1 - 36

Noronha, D., SÁ, M. R., KnOfF, M., Muniz-PereirA, L. C., PINTO, R. M. (2009): Adolpho Lutz e a Coleção Helmintológica do Instituto Oswaldo Cruz, Rio de Janeiro. Rio de Janeiro, Brazil, Museu Nacional, Série Livros 37, 154 pp. Pinto, R. M., Vicente, J. J., Noronha, D. (1994): Nematode parasites of Brazilian accipitrid and falconid birds (Falconiformes). Mem. I. Oswaldo Cruz, 89(3): 359 - 362. DOI: 10.1590/S0074-02761994000300010.

Thiollay, J. M. (1994): FAMily ACCIPITRIDAE. IN: DeL Hoyo, J., Elliott, A., Sargatal, J. (Eds) Handbook of the Birds of the World. Vol. 2. Barcelona, Spain: Lynx Edicions, pp. $52-205$

Travassos, L. (1917): Contribuições para o conhecimento da fauna helmintolojica brazileira. Mem. I. Oswaldo Cruz, 9(1): 5 - 62. DOI: 10.1590/S0074-02761917000100001.

URIBE-PIEDRAHITA, C. (1948): Contribuciones al estudio de la parasitología en Colombia, II. Caldasia, 5(21): 211 - 219 